\title{
Bio-optical properties of the subtropical North Atlantic. II. Relevance to models of primary production
}

\author{
Heather A. Bouman ${ }^{1, *}$, Trevor Platt ${ }^{2}$, Shubha Sathyendranath ${ }^{3}$, Brian D. Irwin ${ }^{2}$, \\ Marcel R. Wernand ${ }^{4}$, Gijsbert W. Kraay ${ }^{4}$
}

\author{
${ }^{1}$ Department of Biology, Dalhousie University, Halifax, Nova Scotia, B3H 4J1, Canada \\ ${ }^{2}$ Bedford Institute of Oceanography, PO Box 1006, Dartmouth, Nova Scotia, B2Y 4A2, Canada \\ ${ }^{3}$ Department of Oceanography, Dalhousie University, Halifax, Nova Scotia, B3H 4J1, Canada \\ ${ }^{4}$ Netherlands Institute of Sea Research, PO Box 59, 1790 AB Den Burg, The Netherlands
}

\begin{abstract}
Based on measurements of phytoplankton biomass, absorption coefficients and photosynthetic performance obtained from samples collected in the subtropical Atlantic Ocean, standard sets of bio-optical parameters were selected and applied to a spectral model of primary production. Computed profiles of instantaneous production, integrated over the day, and spectral irradiance were compared with measurements of $12 \mathrm{~h}$ in situ production and in situ spectral irradiance to assess the model's performance. Although the model performed well for the stations located on the western side of the transect, at the eastern side of the basin the model overestimated both primary production and irradiance below the mixed layer. The modelled irradiance profile was then reconciled with the observations of irradiance by increasing the assumed contribution to absorption by yellow substances. When the production model was re-implemented with the new irradiance values below the mixed layer, the computed and measured production profiles of all the stations were in good agreement. In the spectral model used in this study, the shape of the absorption spectrum of phytoplankton was used as a proxy for the shape of the photosynthetic action spectrum. Because non-photosynthetic pigments (NPPs) were abundant in pigment samples collected in the study region, the influence of NPPs on the shape of the absorption spectrum was examined and its effect on computations of primary production was quantified. When total $a_{\mathrm{ph}}(z, \lambda)$ and photosynthetic $a_{\mathrm{ps}}(z, \lambda)$ phytoplankton absorption at wavelength $\lambda$ and depth $z$ were used to quantify the error resulting from failure to correct for the influence of NPPs on the shape of the absorption spectra, the results showed small errors in the computation of production at depth (up to $20 \%$ ) and integrated, water-column primary production (a maximum of $10 \%$ ).
\end{abstract}

KEY WORDS: Phytoplankton - Primary production - Yellow substances $\cdot$ Non-photosynthetic pigments · Subtropical North Atlantic

\section{INTRODUCTION}

The development of a new generation of satellite, ocean-colour sensors has stimulated the use of serial, synoptic images of phytoplankton biomass to compute global estimates of the rate of carbon fixation by microalgae (Platt \& Sathyendranath 1988). In addition to in-

•E-mail: hbouman@is2.dal.ca corporating information on the chlorophyll field and the penetration of light through the water column, models of primary production must also express the efficiency with which the light absorbed by phytoplankton pigments is converted into photosynthetic product (e.g. Jassby \& Platt 1976, Morel 1978, Platt et al. 1980). In the absence of photoinhibition, the photosynthetic response of phytoplankton to available irradiance can be expressed economically using 2 parameters: the initial slope of the photosynthesis-irradiance (P-I) curve, 
$\alpha^{B}$, and the light-independent rate of photosynthesis, $P_{\mathrm{m}}^{B}$ (Jassby \& Platt 1976, Platt et al. 1980, Sakshaug et al. 1997).

Much of the uncertainty associated with employing primary production models to estimate the rate of carbon fixation by marine phytoplankton in situ lies not in the model's mathematical formulation but rather in assigning values to the photo-physiological and optical parameters (Platt et al. 1991, Morel et al. 1996). To advance our understanding of the spatial and temporal variability of the model parameters, biological oceanographers are working towards the development of an archive of P-I and optical data for the world ocean. One domain for which bio-optical data is particularly wanting is the subtropical open ocean.

During the Deep Chlorophyll Maximum (DCM) expedition, the vertical structure of the bio-optical and photosynthetic properties of subtropical phytoplankton were studied in detail and the results are reported in a companion paper (see Bouman et al. 2000, in this issue). Typically, in oligotrophic waters, the magnitude of phytoplankton biomass, chlorophyll-specific absorption and photosynthetic performance all show strong vertical patterns (e.g. Cullen 1982, Herbland 1983, Babin et al. 1996, Lazzara et al. 1996, Allali et al. 1997) and this vertical variability should be taken into account in bio-optical models of photosynthesis. Moreover, vertical changes in the spectral characteristics of phytoplankton absorption are caused by vertical changes in the concentration of non-photosynthetic pigments (NPPs) relative to photosynthetic pigments (Babin et al. 1996, Allali et al. 1997, Bouman et al. 2000 ). Since the absorption spectrum has been used in models of photosynthesis as a proxy of the shape of the photosynthetic action spectrum (Kyewalyanga et al. 1992, 1997), it has been argued that by not excluding the absorption of NPPs from the spectral shape of the photosynthetic action spectrum, we could introduce significant errors into our calculations of daily watercolumn primary production (Sakshaug et al. 1991, Sosik \& Mitchell 1995).

In general, the shapes of the absorption spectrum and action spectrum $\left({ }^{14} \mathrm{C}\right.$ or fluorescence excitation) of phytoplankton may differ for 2 reasons: the presence of NPPs and a difference in the composition of light-harvesting pigments between the 2 photosystems (Lewis et al. 1986, 1988, Bidigare et al. 1989, Warnock 1990 , Johnsen \& Sakshaug 1996). One method circumventing the problem of NPPs is by selecting the fluorescence excitation spectrum to approximate the shape of the photosynthetic action spectrum, since NPPs do not fluoresce (Sakshaug et al. 1991, Sosik \& Mitchell 1995). Another approach is to subtract out the absorption of NPPs from the absorption spectrum of phytoplankton (Bidigare et al. 1989, Babin et al. 1996, Bouman et al.
2000) based on information on the concentration of photosynthetic and non-photosynthetic pigments and their weight-specific absorption coefficients. It is the latter approach that will be examined in this study.

To address the issues presented above, the photosynthetic and absorptive characteristics of the phytoplankton were studied during a summer expedition to the subtropical North Atlantic. This study covered an extensive area, which provided an opportunity to test the performance of the spectral model proposed by Sathyendranath \& Platt (1989) over a large hydrographic region. The work presented here has 2 main objectives. First, to assess the performance of a spectral model of primary production by comparing the model predictions with in situ primary production measurements. Second, to estimate the error in computed primary production introduced when a total absorption spectrum that includes absorption by non-photosynthetic pigments is used to approximate the shape of the photosynthetic action spectrum.

\section{MATERIALS AND METHODS}

The field data used in this study were collected during the Dutch Deep Chlorophyll Maximum (DCM) cruise. The 5 main stations sampled during the DCM cruise covered a broad swath of the subtropical North Atlantic Ocean (Fig. 1). During transit between stations single CTD casts were taken daily. The samples were collected from July 26 to August 28, 1996 on board the Dutch naval vessel 'Tydeman'.

Shipboard measurements. Some of the physicochemical and biological characteristics of the 5 main stations are summarised in Table 1 . At all 5 stations the mixed-layer depths lie above both the depth of the

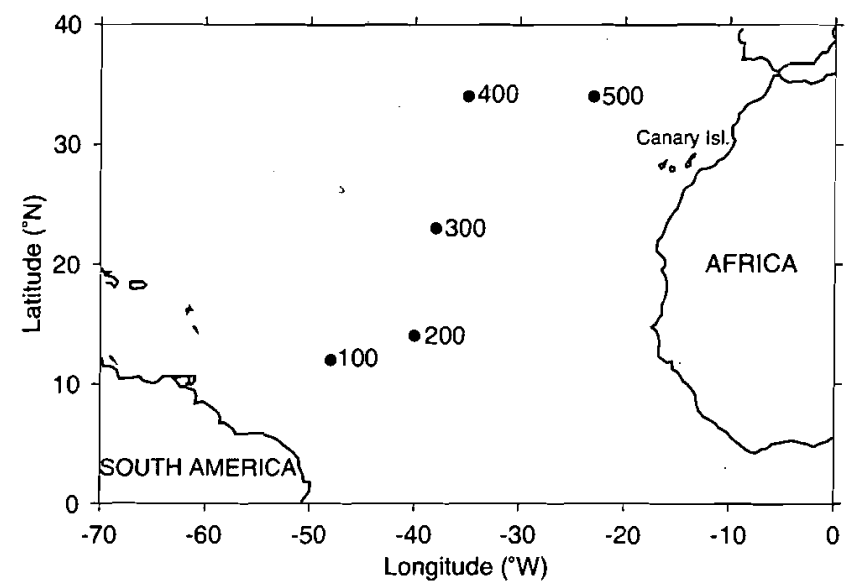

Fig. 1. Map of the 5 major stations sampled during the Deep Chlorophyll Maximum cruise 
chlorophyll maximum and the euphotic depth. Also note that the mixed-layer depths of the 2 eastern-most stations are markedly shallower than those at the 3 western-most stations. Each of the main stations was occupied for $5 \mathrm{~d}$. This allowed sufficient time for depthresolved measurements of the pigment composition, P-I parameters and bio-optical properties of the phytoplankton to be taken at each of the 5 stations.

Chlorophyll a concentrations were determined by fluorescence of the pigment extracts, before and after acidification, using a Turner Designs fluorometer (HolmHansen et al. 1965). To obtain more detailed information on pigment composition, samples were collected at 10 depths, between 10 and $180 \mathrm{~m}$ at each of the timeseries stations. Seawater was filtered through $\mathrm{GF} / \mathrm{F}$ $(47 \mathrm{~mm})$ filters and stored at $-80^{\circ} \mathrm{C}$ for later analysis. Pigment concentrations were determined using reversephase, high-performance liquid chromatography (HPLC) as described in Veldhuis \& Kraay (1990) and Kraay et al. (1992).

Flow-cytometric analysis of samples collected at the 5 stations showed a numerical predominance of Prochlorococcus (M. Veldhuis unpubl. data). In a study by Moore et al. (1995) it was suggested that applying a pathlength-amplification algorithm derived from diatom cultures to a sample dominated by picoplankton (specifically Prochlorococcus) could lead to significant overestimates of phytoplankton absorption coefficients. Therefore, we applied a combination of pathlength-amplification factors (Kyewalyanga et al. 1997) to measurements of the optical densities of particulate matter collected on the filter. The algorithm uses information on the percentage of HPLC chlorophyll a that is divinyl chlorophyll $a$, it attributes this fraction to Prochlorococcus, and applies the pathlength-amplification factor for prochlorophytes (Moore et al. 1995) to this fraction of the sample. The remaining fraction of the chorophyll a was attributed to larger-sized cells and was corrected using the $\beta$-correction algorithm of Hoepffner \& Sathyendranath (1992, 1993). A more detailed description of the filter method used in this study can be found in Bouman et al. 2000.

To examine the depth-dependence of the P-I parameters, water samples were collected at discrete depths throughout the photic zone as described in Bouman et al. (2000). Using the ${ }^{14} \mathrm{C}$ method, samples were inoculated with $20 \mu \mathrm{Ci}$ of ${ }^{14} \mathrm{C}$-labelled sodium bi-carbonate and incubated at 30 different irradiance levels, ranging from ca 2 to $650 \mathrm{~W} \mathrm{~m}^{-2} \mathrm{~s}^{-1}$. The photosynthetic response curves obtained from these experiments were fitted to the exponential function described in Platt et al. (1980) from which the initial slope, $\alpha^{B}$, and the maximum photosynthetic rate, $P_{\mathrm{m}}^{B}$, were derived. Further information on the P-I experimental protocol is described in Bouman et al. (2000).

In situ measurements. In situ primary production experiments were conducted at each station on 3 of the 5 sampling days. One millilitre of $0.2 \mathrm{M} \mathrm{NaH}^{13} \mathrm{CO}_{3}$ working stock was added to 11 of seawater samples collected at $10 \mathrm{~m}$ intervals throughout the euphotic zone. Samples were then incubated for approximately $12 \mathrm{~h}$ (dawn to dusk) in situ and then filtered onto precombusted GF/F filters. The filters were rinsed with filtered seawater, dried and stored for later analysis by mass spectrometry.

On the same water samples ${ }^{14} \mathrm{C}$ in situ incubations were also made. However, the results were systematically high compared with those from the ${ }^{13} \mathrm{C}$ experiments, for reasons unknown. Because the ${ }^{13} \mathrm{C}$ results were consistent with the results of the P-I experiments (see below), we have taken them to be representative of primary production in situ under the prevailing conditions.

Irradiance measurements. Because in situ primary production experiments were conducted in the natural light field, the results were dependent upon the variation in light intensity: it is important to incorporate this variability in irradiance into our computations of primary production. Therefore, photosynthetically active radiation (PAR) at the surface was measured every $5 \mathrm{~min}$ over the duration of the cruise. These PAR data were used to scale the modelled (cloud-free) surface irradiance at each (30 min) time step to produce an irradiance forcing representative of the conditions that prevailed on the days the experiments were conducted. The model's performance was then assessed by comparing the computed estimates of primary production with in situ measurements.

Spectral irradiance was measured using the Advanced Spectral Irradiance Meter (ASIR) (Wernand \& Spitzer 1987). The instrument measured both 
downwelling and upwelling irradiance at 22 spectral bands ranging from 400 to $720 \mathrm{~nm}$. Measurements of UV irradiance at $320 \mathrm{~nm}$ were also made using a Biospherical Profiling Ultraviolet Radiometer (PUV-500).

Spectral model of primary production. In the open ocean, the vertical distribution of chlorophyll $a$ is highly structured, and is usually characterised by a pronounced subsurface chlorophyll maximum (Cullen 1982). Information on the vertical structure of the biomass profile is vital for prediction of both the underwater-light field and water-column primary production (Platt et al. 1988). Since the information on chlorophyll $a$ concentration obtained by satellite is heavily weighted toward the sea surface, we must rely on ship-board measurements to determine the depth variation in chlorophyll $a$ concentration. The shape of the phytoplankton biomass profiles can be expressed as a standard function of depth using the following equation (Platt et al. 1988):

$$
B(z)=B_{0}+\frac{h}{\sigma \sqrt{2 \pi}} \exp -\frac{\left(z-z_{\mathrm{m}}\right)^{2}}{2 \sigma^{2}}
$$

where $B(z)$ is chlorophyll biomass as a function of depth $z ; z_{\mathrm{rm}}$ is the center of the Gaussian peak (corresponding to the depth of the maximum chlorophyll concentration); and $\sigma$ and $h$ are related to the width and area of the peak, respectively. The 4 parameters obtained by fitting this shifted Gaussian curve to measured chlorophyll concentrations can then be used in implementations of the primary-production algorithm.

Because phytoplankton absorption contributes strongly to the attenuation of underwater light, and because this absorption is strongly wavelength-dependent, it has an important impact upon the spectral properties of the irradiance field. In addition, the spectral-dependence of phytoplankton absorption is mirrored in the spectraldependence of the light-limited photosynthetic rate $\left[\alpha^{B}(\lambda)\right]$, known as the photosynthetic action spectrum (Haxo \& Blinks 1950, Lewis et al. 1988, Kyewalyanga et al. 1997). Since both irradiance and the light-limited photosynthetic rate demonstrate strong wavelength dependence, it would seem logical to incorporate the spectral characteristics of both of these quantities into primary production algorithms (Schofield et al. 1991). It has been shown that estimates obtained by wavelength-resolved computations of water-column primary production can differ significantly from those estimates obtained using broad-band (wavelength-independent) models (Sathyendranath et al. 1989, Kyewalyanga et al. 1992). The discrepancy between estimates generated from broad-band and spectral models suggests that by ignoring the wavelength-dependence of both irradiance and light-limited photosynthetic rates, one may introduce a serious bias in the estimation of watercolumn primary production (Kyewalyanga et al. 1992).
In the following paragraphs we will describe in detail the fundamental components of the P-I model used in the present study. For simplicity, we will begin by repressing the spectral dependence of the model and examining the key model inputs in their non-spectral form. This will be followed immediately by a detailed description of how the spectral dependence of light-limited photosynthesis, phytoplankton absorption and underwater irradiance is treated in our spectrally-resolved model of primary production.

For broad-band (wavelength-independent) models of photosynthesis, available light is expressed as the sum of radiant energy taken over the photosynthetic waveband, which covers the spectral range of 400 to $700 \mathrm{~nm}$. In aquatic environments, PAR decreases in a systematic manner with depth (Kirk 1994). The rate at which the underwater light is attenuated with increasing depth can be expressed mathematically as follows:

$$
I(z)=I(0) \mathrm{e}^{-z K_{\mathrm{d}}(z)},
$$

where $I(z)$ is PAR at depth $z$ (positive, downwards), $I(0)$ is surface PAR, and $K_{\mathrm{d}}(z)$ is the diffuse vertical attenuation coefficient for downwelling PAR at depth $z$ (Kirk 1994).

The optical components responsible for the attenuation of underwater irradiance are pure water, phytoplankton biomass, and dissolved and particulate yellow substances (Kirk 1994). Therefore, $K_{\mathrm{d}}(z)$ can be written as the sum of the attenuation coefficients of the components:

$$
K_{\mathrm{d}}(z)=K_{\mathrm{w}}(z)+K_{\mathrm{ph}}(z)+K_{\mathrm{ys}}(z),
$$

where $K_{\mathrm{w}}(z), K_{\mathrm{ph}}(z)$ and $K_{\mathrm{ys}}(z)$ are the attenuation coefficients of pure water, phytoplankton and yellow substances, respectively. Once $K_{\mathrm{d}}(z)$ is known, one can estimate PAR at any given depth by using the relationship shown in Eq. (2).

In P-I equations, the light-limited rate of photosynthesis at depth $z\left[\alpha^{B}(z)\right]$ and irradiance at depth $z[I(z)]$ occur together as a product. Using the symbol $\Pi^{B}(z)$ to represent this product (Platt \& Sathyendranath 1988), we have:

$$
\Pi^{B}(z)=\alpha^{B}(z) I(z)
$$

To convert our broad-band model of primary production to a spectral one will require that the quantities $\alpha^{B}$ and $I(z)$ be expressed in their spectral form. Thus, Eq. (4), when expressed as a function of wavelength $\lambda$, becomes:

$$
\Pi_{\lambda}^{B}(z)=\int_{400}^{700} \alpha^{B}(z, \lambda) I(z, \lambda) \mathrm{d} \lambda .
$$

Thus, spectral photosynthesis-light models can be developed from non-spectial models if we replace the product $\Pi^{B}=\alpha^{B} I$ by $\Pi_{\lambda}^{B}$ everywhere. Note that this implies that $K_{\mathrm{d}}(z)$ in Eq. (3) be replaced by its spectral 
equivalent, $K_{\mathrm{d}}(z, \lambda)$, to compute $I(z, \lambda)$, which in turn implies that the attenuation coefficients for the model components also be resolved spectrally. The absorption and backscattering properties of all materials contribute to the spectral variability of $K_{\mathrm{d}}(z, \lambda)$ with depth according to the following relationship (Sathyendranath \& Platt 1989):

$$
K_{\mathrm{d}}(z, \lambda)=\frac{a(z, \lambda)+b_{\mathrm{b}}(z, \lambda)}{\cos \theta_{\mathrm{d}}}
$$

where $a\left(z_{1} \lambda\right)$ is the absorption coefficient at wavelength $\lambda$ and depth $z, \quad b_{\mathrm{b}}(z, \lambda)$ is the corresponding backscattering coefficient and $1 / \cos \theta_{d}$ defines the mean pathlength of the light in water, per unit vertical excursion. The absorption and back-scattering coefficients can be expressed as the sum of their components (water, yellow substances and phytoplankton), analogous to Eq. (3) for $K_{\mathrm{d}}$.

When rewritten in its spectral form, the model of Platt et al. (1980) becomes:

$$
P^{B}(z)=P_{\mathrm{m}}^{B}(z)\left\{1-\exp \left[-\Pi_{\lambda}^{B}(z) / P_{\mathrm{m}}^{B}(z)\right]\right\} .
$$

This equation can be used to estimate production at a discrete depth. Using the trapezoid rule, production in discrete depth intervals can be integrated throughout the water column to arrive at an estimate of instantaneous water-column production. It is conventional practice that this integration be carried out from the sea surface down to the depth at which irradiance is $1 \%$ of the surface value (i.e. $1 \%$ PAR) (Sakshaug et'al. 1997). In very clear, open-ocean waters, where cells are adapted to harvest extremely low irradiances, it has been suggested that the integration of production be carried out to the $0.1 \%$ light level (Sakshaug et al. 1997), and this is the value adopted in the work presented here. To estimate daily water-column production, estimates of instantaneous water-column production are calculated for evenlyspaced time intervals from dawn to dusk and then summed.

In addition to incorporating the spectral variability of the underwater-light field, models of photosynthesis should also embody the angular distribution of irradiance. It has been demonstrated that angular effects of irradiance can be significant for calculations of primary production, especially in cases where the biomass profile is highly structured (Sathyendranath \& Platt 1989). Therefore, in the model used in the current study, the angular dependence of the underwater light field was incorporated using the algorithm presented in Sathyendranath \& Platt (1989). The clear-sky model of Bird (1984) was used to estimate the direct and diffuse components of irradiance incident at the sea surface. The zenith angular distribution of the underwater light field, necessary for the computation of $K_{\mathrm{d}}(z, \lambda)$ (see Eq. 6), was then computed as in Sathyendranath \& Platt (1989), given station location and local time. Input parameters derived from photosynthesis-light experiments and absorption measurements gathered in the field were used in the calculation of daily, water-column primary production. The selection of these parameters are discussed next.

Selection of input parameters. P-I data were used to calculate mean values of $\alpha^{B}$ and $P_{\mathrm{m}}^{B}$ for 3 distinct layers of the water column: above and below the DCM (Table 2). The depths used to define the discrete layers were derived from the parameters $\sigma$ and $z_{\mathrm{m}}$ that were used to characterise the chlorophyll profile (see Eq. 1). The first depth interval ranged from the surface to $\left(z_{\mathrm{m}}-1.5 \sigma\right)$. The second depth interval was given the range $\left(z_{m}-1.5 \sigma\right)$ to $\left(z_{m}+1.5 \sigma\right)$. The third depth interval extended from the depth denoted by $\left(z_{\mathrm{m}}+1.5 \sigma\right)$ to the base of the euphotic zone, which was defined as that depth where PAR was $0.1 \%$ of its surface value. As in the study of Bouman et al. (2000), we used $P_{\mathrm{m}}^{B}$ values from samples collected near local noon in this modelling exercise. For the upper layer, mean parameters were calculated only from samples collected close to the sea surface ( 5 to $10 \mathrm{~m}$ ) to avoid underestimation of surface production through use of parameters of photoacclimated phytoplankton. In the case of the middle and lower layers, mean P-I parameters were calculated from all of the samples collected within the depth interval.

The justification for applying standard sets of photosynthesis parameters to each of 3 distinct layers is 2 -fold: first, it provides a test of the hypothesis that a

Table 2. Mean values of the photo-physiological parameters for 3 discrete layers of the water column (above, within and below the DCM) defined with reference to the 5 main sampling stations. For each parameter, the mean is shown followed by the coefficient of variation (\%) and $N$ (number of observations) in parentheses. Depth intervals were determined by the parameters $z_{\mathrm{m}}$ and $\sigma$ of the shifted Gaussian function used to characterise the subsurface chlorophyll a maximum. The symbol $z_{\mathrm{t}}$ denotes the depth up to

\begin{tabular}{|c|c|c|c|}
\hline Depth interval & $\begin{array}{l}\text { Definition } \\
\text { (m) }\end{array}$ & $\frac{P_{\mathrm{m}}^{B}}{\left[\mathrm{mg} \mathrm{C}(\mathrm{mg} \mathrm{chl} a)^{-1} \mathrm{~h}^{-1}\right]}$ & $\begin{array}{c}\alpha^{B} \\
{\left[\underset{\left.\left(\mathrm{W} \mathrm{m} \mathrm{m}^{-2} \mathrm{~s}^{-1}\right)^{-1}\right]}{-1} \mathrm{~h}^{-1}\right.}\end{array}$ \\
\hline Above DCM & 0 to $\left(z_{m}-1.5 \sigma\right)$ & $5.67(21 \%, 3)$ & $0.07(14 \%, 4)$ \\
\hline Within DCM & $\left(z_{\mathrm{m}}-1.5 \sigma\right)$ to $\left(z_{\mathrm{m}}+1.5 \sigma\right)$ & $2.30(33 \%, 10)$ & $0.11(55 \%, 25)$ \\
\hline Below DCM & $\left(z_{m}+1.5 \sigma\right)$ to $z_{t}$ & $1.16(15 \%, 9)$ & $0.20(25 \%, 9)$ \\
\hline
\end{tabular}
which water-column production is integrated 
standard array of photosynthetic parameters can describe adequately the vertical structure of primary production over this stretch of the ocean in a particular season; and, second, it allows one of the most commonly measured biological variables to be used to determine the vertical structure of the photosynthetic parameters.

According to Eq. (3), there are 3 main components of the aquatic medium that are responsible for the attenuation of underwater irradiance: pure water, phytoplankton and yellow substances. The vertical attenuation of light by these substances is dependent on the absorptive and backscattering characteristics of each of these 3 components (see also Eq. 6), and we now discuss how they were treated in our spectral model of primary production.

Absorption by phytoplankton throughout the water column $a_{\mathrm{ph}}(z, \lambda)$ necessary to compute the total absorption coefficient $a(z, \lambda)$ in Eq. (6), was estimated as follows. First, absorption by phytoplankton at $440 \mathrm{~nm}$ $\left[a_{\mathrm{ph}}(440)\right]$ measured using the filter technique and fluorometrically-determined chlorophyll concentration were pooled across all stations and depths and fitted to a Michaelis-Menten function:

$$
a_{\mathrm{ph}}(440)=\frac{A S B}{S+A B},
$$

where $A$ is the initial slope of the curve, $S$ is the saturation parameter, and $B$ is the concentration of chlorophyll $a$. By fitting the data to Eq. (7), we obtained parameter values of 0.094 and 0.277 for $A$ and $S$, respectively. The non-linear regression yielded an $\mathbf{r}^{2}$ value of $0.83(n=48)$. Using the Michaelis-Menten equation and the shifted-Gaussian chlorophyll profile $[B(z)]$, absorption of phytoplankton at $440 \mathrm{~nm}$ at depth $z\left[a_{\mathrm{ph}}(440)\right]$ could be estimated. Spectral absorption by phytoplankton at depth $z\left[a_{\mathrm{ph}}(z, \lambda)\right]$ was then computed by scaling a mean absorption spectrum of phytoplankton normalised to $440 \mathrm{~nm}$ to the estimated value of $\left[a_{\mathrm{ph}}(440)\right]$. The mean absorption spectrum was obtained by averaging the absorption spectra collected at all stations and depths.

The absorption by both coloured dissolved organic matter and particulate detrital material (yellow substances) was expressed as a percent of absorption by phytoplankton and water at $440 \mathrm{~nm}$. In the initial version of the model, this percentage contribution was assumed to be $30 \%$ at all stations. The absorption by these substances at $440 \mathrm{~nm}\left[a_{\mathrm{ys}}(440)\right]$ was then used to scale the absorption spectrum of yellow substances normalised to $440 \mathrm{~nm}\left[a_{Y \mathrm{~s}}^{440}(440)\right]$, which was assumed to have the exponential form

$$
a_{y s}^{440}(\lambda)=\exp [-0.014(\lambda-440)]
$$

(Bricaud et al. 1981) [ie. $\left.a_{y s}(\lambda)=a_{y s}^{40}(\lambda) a_{y s}(440)\right]$. The absorption spectrum of pure water was based on the analysis of Pope \& Fry (1997). The total absorption coefficient $a(z, \lambda)$ in Eq. (6) was estimated as the sum of the absorption by water, yellow substances and phytoplankton.

The backscattering coefficients of water and phytoplankton [necessary to estimate $K_{\mathrm{d}}(z, \lambda)$ according to Eq. 6] were derived from relationships described in Morel (1974) and Sathyendranath \& Platt (1988), respectively. Backscattering by yellow substances was assumed to be negligible.

Standard sets of photo-physiological parameters were selected for the entire sampling area and were used in a spectral model of primary production. The only model parameters that were allowed to vary from station to station in the initial calculations were those describing the vertical structure of chlorophyll a concentration (Table 3). Estimates obtained using the spectral model were then compared with in situ production measurements to assess the performance of the primary production model as follows. First, estimates of daily primary production at depth and their corresponding in situ production measurements were compared to determine whether the shape and magnitude of the 2 production profiles were in agreement. Second, values of daily, integrated water-column production estimated from the model were compared with those calculated from in situ production data.

\section{RESULTS AND DISCUSSION}

When assessing the predictive ability of a model, data on input parameters (e.g. photo-physiological and bio-optical data) and in situ measurements of the model outputs (e.g. spectral irradiance and primary production) should be collected at similar spatial and temporal scales. In this study, such data were made available for detailed analysis of the model predictions. The model results, using model parameters selected according to the discussion in the preceding paragraphs and surface irradiance measurements, are shown in Fig. 2. Reasonable agreement between the

Table 3. Biomass profile parameters for 5 main stations sampled during the DCM cruise

\begin{tabular}{|lrrrr|}
\hline Stn & \multicolumn{4}{c|}{ Biomass profile parameters } \\
& $z_{\mathrm{m}}$ & $B_{\mathbf{0}}$ & \multicolumn{1}{c|}{$\sigma$} & \multicolumn{1}{c|}{$h$} \\
\hline 100 & 72.46 & 0.112 & 17.10 & 9.85 \\
200 & 89.54 & 0.072 & 22.42 & 11.27 \\
300 & 107.62 & 0.058 & 26.05 & 9.13 \\
400 & 89.42 & 0.061 & 19.07 & 9.33 \\
500 & 89.15 & 0.071 & 17.87 & 6.58 \\
\hline
\end{tabular}


vertical structure of primary production in the model output and that in the observations was found at Stns 100, 200 and 300: both the shapes and magnitudes of the modelled production profiles are similar to those of the actual in situ profiles. However, in the cases of Stns 400 and 500, the vertical profiles of modelled and measured production diverged markedly below the mixedlayer depth. Further, at depths where in situ production values had fallen close to 0 , the model predicted substantial levels of production.

Differences in the duration of P-I experiments and the in situ production incubations ( $3 \mathrm{~h}$ versus $12 \mathrm{~h}$, respectively) could explain the observed discrepancy between the profiles of production generated from the $\mathrm{P}-\mathrm{I}$ model and the measured production values. The

$$
P(z)\left(\mathrm{mg} \mathrm{C} \mathrm{m}^{-3} \mathrm{~d}^{-1}\right)
$$
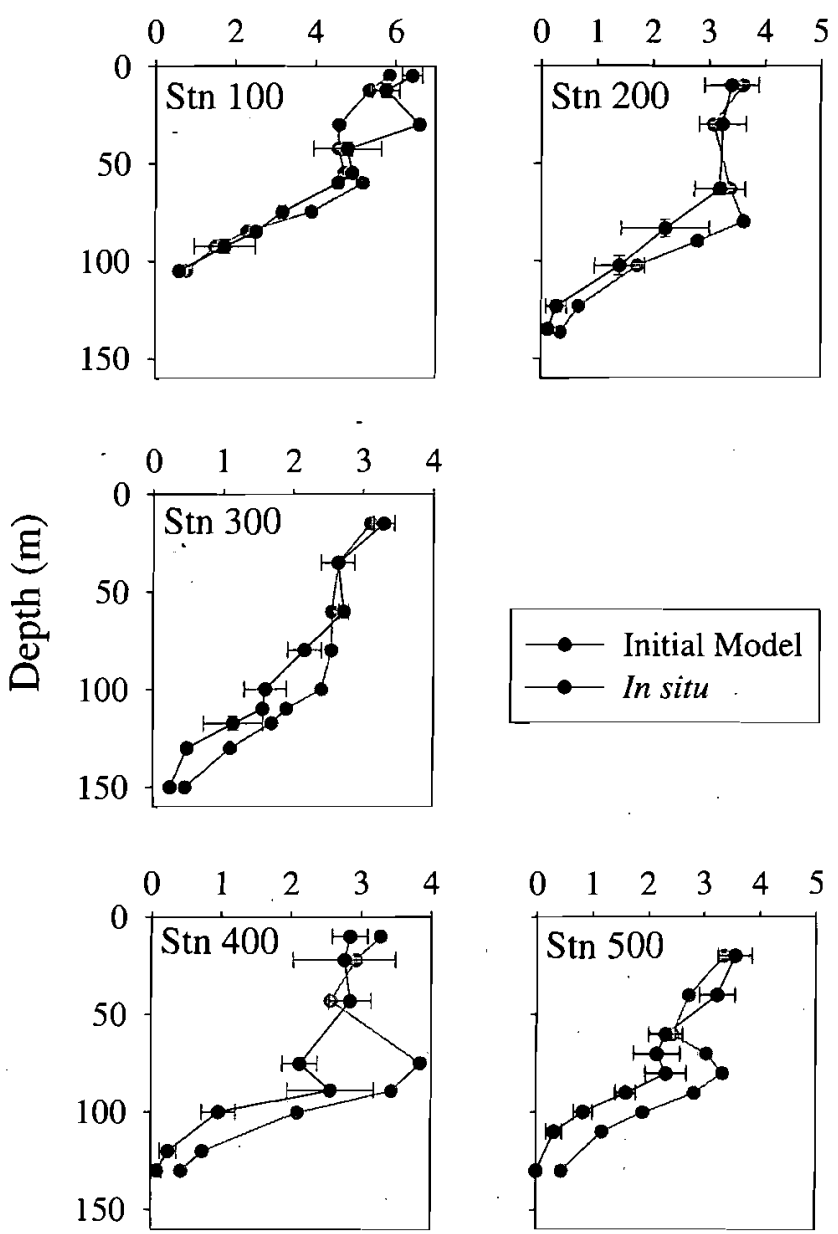

Fig. 2. Mean vertical profiles of modelled primary production using the initial set of input parameters and in situ ${ }^{13} \mathrm{C}$ primary production measurements. Mean values of in situ production were computed from 2 sets of observations for Stn 100 and 3 sets of observations for Stns 200 to 500. Error bars shown on the in situ profiles represent \pm 1 standard deviation from the mean results obtained from the $12 \mathrm{~h}$ in situ incubations may be more strongly influenced by time-dependent processes that affect the net amount of carbon incorporated into algal cells (e.g. community respiration) than those from the P-I experiments. However, it is puzzling that the discrepencies between modelled and in situ primary production occurred predominately at depth (Stns 300, 400, 500). If the modelled estimates were taken to be true, we would conclude that phytoplankton found within and below the DCM contributed substantially to the overall water-column primary production. Because one of the aims of the study was to assess the ecological importance of the chlorophyll maximum, these results were examined more closely.

Errors in the estimation of primary production at depth could originate from the misrepresentation of 3 elements in the model: the biomass profile, the photosynthetic parameters and the underwater light field. It is important to note that the biomass profile is also utilised in the estimation of attenuation of light by phytoplankton, and therefore any error associated with the estimation of $B(z)$ would, necessarily, carry over to the estimation of the underwater light field. In the following discussion, the likelihood of errors in the measurements of chlorophyll biomass and the P-I parameters will be examined.

The biomass profiles used in the models were derived from repeated measurements of the fluorometrically-determined chlorophyll a concentration, which were taken over a $5 \mathrm{~d}$ sampling period at discrete depths. The biomass profiles presented in Bouman et al. (2000) show that the variation in the chlorophyll $a$ concentrations was relatively small at all depths, despite the vertical oscillation of the profile caused by internal waves. Because measurements of chlorophyll a concentration were similar in their magnitude and variability at all of the stations, it would be unlikely that the biomass profiles were the source of the between-station differences in the modelled and measured primary-production profiles.

The P-I parameter $\alpha^{B}$, which is the initial slope of the light saturation curve, governs primary production calculations in the light-limited regions of the water column. One possible explanation for the overestimation of production at depths close to the DCM, where light levels are low, could be that the value assigned to $\alpha^{B}$ was biased in a positive manner. Although the standard errors associated with the P-I parameters were high compared with measurements of chlorophyll concentration (see Bouman et al. 2000), the magnitudes of $\alpha^{B}$ at these depths were within the range of those found in other open-ocean studies (Cullen et al. 1992, Platt et al. 1992, Babin et al. 1996). Thus, there is no strong case for dismissing the estimates of $\alpha^{B}$ obtained in this study. 
The overestimation of production at depth can also occur if the modelled irradiance is greater than the actual in situ light values. This possibility is examined in detail in the following section.

\section{Refinements to the model using measurements of spectral irradiance}

To determine if a misrepresentation of modelled spectral irradiance was reponsible for the discrepancy between computed and measured production, vertical profiles of modelled spectral irradiance were compared with measured spectral irradiance at specific wavebands. Generally, the irradiance derived from the clear-sky model matched that observed in the mixed layer tolerably well (Fig. 3). In the case of Stn 200, where intermittent clouds were present, the observed irradiance was understandably lower. Although our model does correct for the occurrence of clouds at intervals throughout the day, the difference between the resolution of the measured incident irradiance and the time step of the model integration may contribute to the differences in the magnitudes of the 2 profiles.

Below the mixed layer, however, a divergence in the slopes of the measured and modelled irradiance profiles was found in the blue wavebands, especially at Stns 400 and 500 , whereas in the green wavebands the slopes of modelled and measured irradiance profiles corresponded well. Phytoplankton photosynthesis is strongly influenced by the availability of blue light for several reasons (Kirk 1976). First, absorption by chlorophylls and carotenoids is strongest in the blue-green region of the spectrum. Although chlorophylls also absorb in the red region of the spectrum, the amount of available light in these wavebands is extremely limited due to its strong attenuation by pure water in the surface waters (Kirk 1976). Second, the photosynthetic action spectra of most eukaryotic phytoplankton have an intense peak in the blue-green region of the spectrum (Haxo \& Blinks 1950, Lewis et al. 1988, Kyewayanga et al. 1997). Thus, computations of primary production would be strongly influenced by the amount of bluegreen light estimated by the light-attenuation algorithm. To reconcile the modelled irradiance profile with the measured values, the contribution of yellow substances to total absorption at $440 \mathrm{~nm}$ was increased beneath the mixed layer, as justified below.

One strong absorber of blue light in the open ocean is marine phytoplankton. Thus, an underestimation of phytoplankton absorption could lead to the discrepancy between modelled and measured spectral irradiance described above. Therefore we re-examined the phytoplankton absorption data used to derive the contribution of phytoplankton to light attenuation in our spectral model of primary production. The absorption coefficients of phytoplankton measured in this study region were extremely high, and at the $676 \mathrm{~nm}$ waveband, phytoplankton absorption coefficients often exceeded the absorption coefficient of pure chloro-

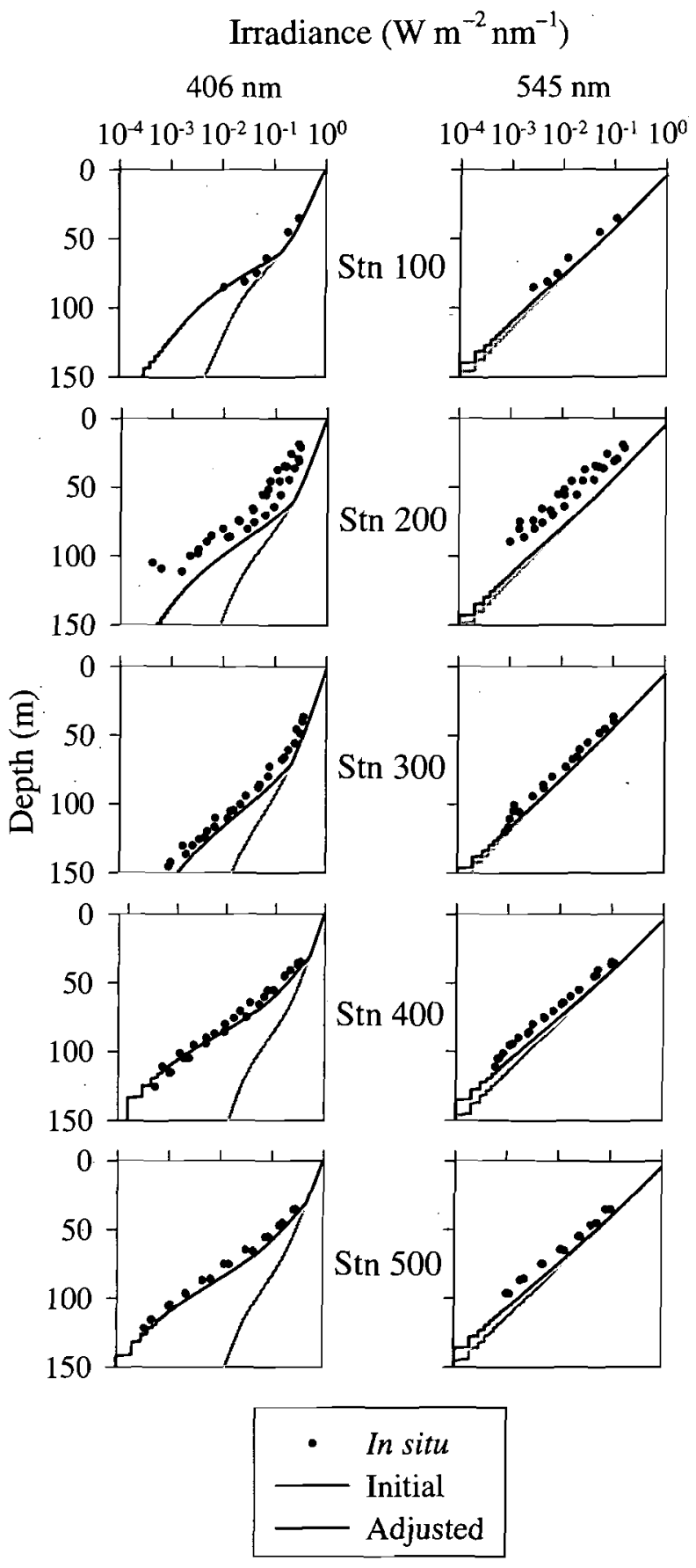

Fig. 3. Vertical profiles of computed irradiance at $406 \mathrm{~nm}$ and $545 \mathrm{~nm}$ using the initial and adjusted production model. Measured in situ irradiance profiles are also shown 
phyll $a$ in solvent (Bouman et al. 2000). Thus, it is doubtful that the absorption coefficients of phytoplankton were grossly underestimated at these stations. Therefore, if we dismiss errors in phytoplankton absorption as a possible explanation for the discrepancy between the modelled and measured irradiance profile, we are left with the absorption due to detritus and dissolved materials (yellow substances) as potential sources of error.

Little is known of the optical significance of yellow substances in the open ocean: In these so-called Case I waters, phytoplankton biomass is considered to be the dominant factor regulating the spatial and temporal variability in the optical properties of the water column (Morel 1980). Earlier studies by Prieur \& Sathyendranath (1981) and Bricaud et al. (1981) attributed only a small proportion of total absorption of visible light to yellow substances. However, these studies examined samples collected near the sea surface: recent studies of the optical characteristics of oligotrophic waters off Bermuda provide strong evidence that attenuation of light by non-algal components, especially during the summer months below the mixed layer, may be more important than previously believed (Siegel \& Michaels 1996, Nelson et al. 1998).

In spectral models of light attenuation used in this and other studies designed for application in Case I waters, the absorption by yellow substances is assumed to be proportional to absorption by phytoplank-

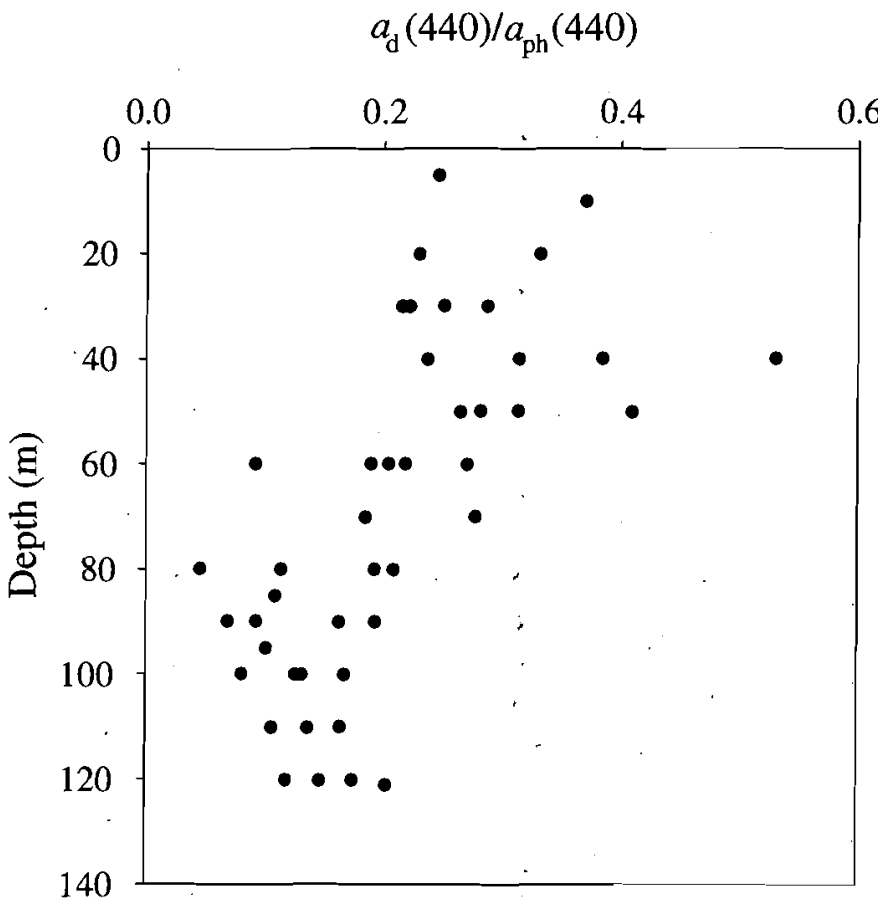

Fig. 4. Vertical profiles of the ratio of absorption by detritus at $440 \mathrm{~nm}$ to the absorption by phytoplankton at $440 \mathrm{~nm}$ ton (Sathyendranath \& Platt 1988, Morel et al. 1996). Yet, recent studies have shown that seasonal and vertical changes in the absorption by yellow substances are not correlated with variations in either phytoplankton absorption or chlorophyll concentration in the subtropical open-ocean waters (Siegel \& Michaels 1996, Nelson et al. 1998). Thus, it may be necessary to abandon the assumed dependence of absorption by dissolved yellow substances on phytoplankton absorption in our ocean-colour and light-attenuation models (Siegel \& Michaels 1996, Garver \& Siegel 1997).

To determine whether absorption by particulate, non-algal (detrital) components could account for the difference between measured and modelled irradiance profiles, values of particulate detrital absorption, which were estimated by taking the difference between total particulate absorption and absorption by phytoplankton after extraction, were examined. Fig. 4 shows the proportion of absorption by detritus at $440 \mathrm{~nm}$ relative to that of phytoplankton at the same wavelength at all depths for the 5 stations. As in the study by Nelson et al. (1998), detrital absorption at $440 \mathrm{~nm}$ was roughly proportional to absorption by phytoplankton. For all of the stations, detrital absorption rarely exceeded $30 \%$ of phytoplankton absorption at $440 \mathrm{~nm}$ and usually fell below this value in the deeper samples. Since $30 \%$ was the proportion of absorption at $440 \mathrm{~nm}$ that was initially assigned to absorption by both detrital and dissolved coloured material in our light-attenuation algorithm, and particulate detrital absorption could not account for the strong absorption of visible light at the blue wavebands below the mixed layer, only the dissolved component of light absorption remains as a possible source of the unexplained absorption of blue light at depth

Variation in the magnitude of absorption by coloured dissolved organic materials (CDOM) in the open ocean can be a result of photochemical degradation of CDOM at the surface, accumulation of CDOM by biological processes or intrusion of a CDOM-rich water mass from an outside source. Although salinity measurements do not provide strong evidence that another water mass was responsible for the increase in CDOM below the mixed layer, this possibility cannot be entirely ruled out. However, there is little doubt that photodegradation of CDOM occurs continuously within the mixed layers of these clear, stratified waters and is a possible mechanism for the apparent low attenuation of blue light in the surface waters. In the studies of Siegel \& Michaels (1996) and Nelson et al. (1998) the largest vertical gradient in absorption by non-algal material was found in the summer. Low concentrations of CDOM in the surface waters were attributed to strong irradiance levels within the mixed layer causing photobleaching of CDOM (Siegel \& Michaels 1996, 
Nelson et al. 1998). Below the mixed layer, however, CDOM accumulated throughout the summer months (Siegel \& Michaels 1996, Nelson et al. 1998).

In the present study, matching the measured spectral irradiance values to the modelled estimates for all of the stations required an increase in the proportion of absorption by yellow substances at $440 \mathrm{~nm}$ to that of phytoplankton absorption at $440 \mathrm{~nm}$ below the mixed layer from $30 \%$ to as much as $120 \%$ (Fig. 3). As expected, this increase did not compromise the good agreement between modelled and measured irradiance at $545 \mathrm{~nm}$ already obtained using the initial optical parameters.

It is conceded that the presumed increase below the mixed layer in the relative importance of absorption by yellow substances to tune the optical model is arbitrary. However, there is independent support for this modification. It is well known that yellow substances absorb strongly in the UV region (Jerlov 1968, Kirk 1976) (see Eq. 9). Therefore, an increase in concentration of yellow substances below the mixed layer would lead to a corresponding increase in the attenuation coefficient of UV irradiance below the mixed layer. Fortunately, profiles of UV irradiance were taken during the DCM cruise using a Profiling Ultraviolet Radiometer (I. Obernosterer unpubl. data) and allowed us to determine whether such an increase in UV attenuation took place. Profiles of the attenuation coefficient of irradiance at $320 \mathrm{~nm}[K(z, 320)]$ were computed from underwater irradiance data as follows. First, irradiance measurements were binned at $1-\mathrm{m}$ intervals. Then, attenuation coefficients were derived from the binned irradiance values using a least-squares regression. The regressions were made over $10 \mathrm{~m}$ intervals at $5 \mathrm{~m}$ increments. The computed values of $K(z, 320)$ are shown in Fig. 5 .

To assess whether the increase in absorption by yellow substances in our light-attenuation model was consistent with profiles of $K(z, 320)$, the attenuation of UV irradiance at $320 \mathrm{~nm}$ was estimated using the spectral form of yellow substance absorption defined in Eq. (9); values of yellow substance absorption at $440 \mathrm{~nm}$ used in our adjusted underwaterirradiance model; and values of absorption and backscattering by seawater at $320 \mathrm{~nm}$ obtained from Smith \& Baker (1981) and Morel (1974), respectively. In the absence of data on UV absorption by phytoplankton, we assumed that absorption and scattering of the particulate fraction were negligible based on the low chlorophyll concentrations at the surface, where mycosporine-like amino acids would most likely be abundant (Negri et al. 1992). The profiles of the computed attenuation coefficient are also shown in Fig. 5 and appear to model adequately the shape of the profile of $K(z, 320)$ derived from the in situ irradiance measurements. There is a positive shift in the computed profile relative to the observed one. This could result from the choice of the absorption coefficients for pure water used in our computation of $K(z, 320)$. The measurements of $a_{w}(\lambda)$ reported by Smith \& Baker (1981) were made on the clearest nat: ural waters, and consequently will include some absorption by CDOM and particulates, and therefore may be slightly higher than $a_{w}(\lambda)$ for pure water itself. Nevertheless, by adjusting the amount of absorption by yellow substances based on irradiance measurements in the blue and green regions of the spectrum, the change in attenuation of UV irradiance near the depth of the mixed layer was satisfactorily predicted. This provides corroborating evidence that the missing component of absorption in the initial model had a spectral form similar to that of yellow substances.

A marked increase in absorption by CDOM below the mixed-layer depth has been documented in other studies. A decrease in both fluorescence and absorption by CDOM in the mixed layer has been observed in coastal regions (Vodacek et al. 1997). Vertical changes in the absorption of non-algal coloured material have also been shown in the open ocean, where absorption by non-algal coloured material is relatively low at the surface and significantly higher at depth (Siegel \& Michaels 1996). Furthermore, the assignment of nearly equal absorption by non-algal coloured material and phytoplankton below the mixed layer at $440 \mathrm{~nm}$ in our

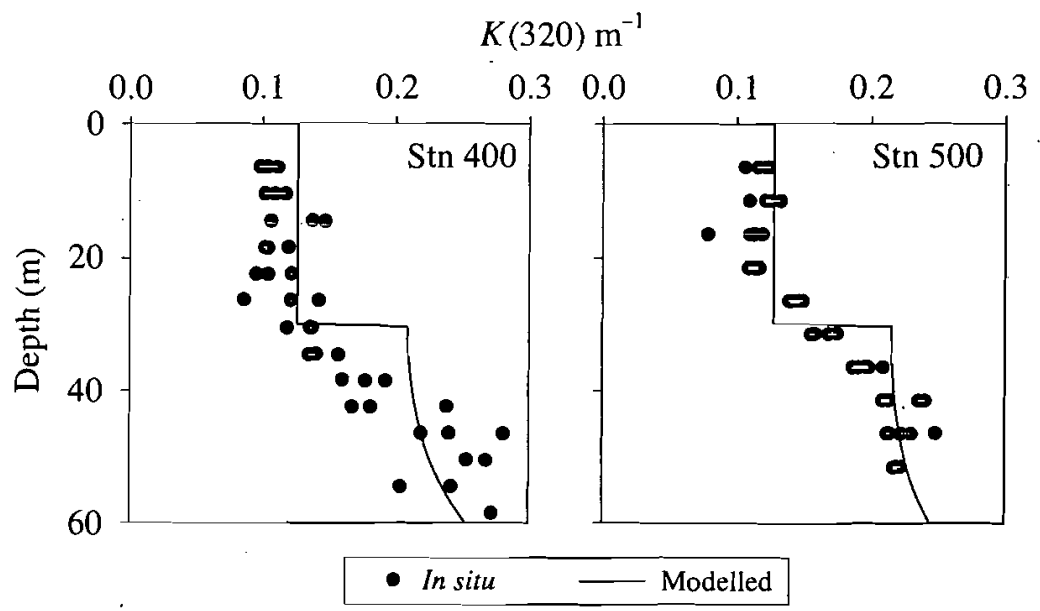

Fig. 5. Vertical profiles of the attenuation coefficient of downwelling irradiance at $320 \mathrm{~nm} K(z, 320)$ computed from a profiling UV radiometer. The solid line represents estimates of $K(z, 320)$ based on the contribution of yellow substances to total absorption used in our adjusted light-attenuation algorithm and values of absorption and scattering of pure water taken from Smith \& Baker (1981) and Morel (1974), respectively 
spectral model of light attenuation is supported by results obtained in the studies of Siegel \& Michaels (1996) and Nelson et al. (1998). At the Bermuda Time Series (BATS) station it was estimated that, below the mixed layer, the attenuation coefficients of light due to non-algal coloured material at $440 \mathrm{~nm}$ approached values of attenuation due to phytoplankton (Siegel \& Michaels 1996). This estimate was confirmed in a detailed optical study by Nelson et al. (1998) conducted at the BATS site, in which it was found that absorption by CDOM at $440 \mathrm{~nm}$ constituted more than half of the total non-water absorption coefficient.

When the primary production model was re-implemented using the new optical parameters, the predicted primary production values below the mixedlayer depth at Stns 300,400 and 500 were close to the in situ primary production measurements (Fig. 6), with both profiles approaching values of 0 production at approximately the same depth. This suggests that the underestimation of absorption by yellow substances at depth was responsible for the discrepancy between the production estimates made by the initial model and in situ production measurements. The absorption by yellow substances had an impact on the computation of primary production by changing the spectral quality and intensity of the underwater light field, which, in turn, affected both the depth at which light becomes limiting for photosynthesis and the depth to which the model integrates the computed production values (in this case the $0.1 \%$ light level). Stns 400 and 500, with their shallow mixed layers, were most affected by the underestimation of absorption by yellow substances. At these stations a large fraction of the photic zone lies beneath the mixed layer depth (Table 1). Increasing the amount of blue light in this fraction of the water column strongly diminished the total amount of light available for photosynthesis deeper in the water column. Changing the amount of absorption by yellow substances below the mixed layer also improved markedly the estimates of daily, integrated, water-column primary production, as illustrated in Fig. 7. The estimates from the adjusted model fell very close to the $1: 1$ line, whereas the initial model results all fell well above the line, in some cases overestimating primary production by as much as $30 \%$.

Results obtained in this modelling exercise reinforce the need to develop a better understanding of the relative importance of all absorptive substances present in aquatic environments. More emphasis should be placed on obtaining optical measurements of yellow substances from season to season over a range of trophic conditions. It is conceivable, based on data presented in this and other studies (Siegel \& Michaels 1996, Nelson et al. 1998), that, even in the open ocean, absorption by yellow substances may vary in
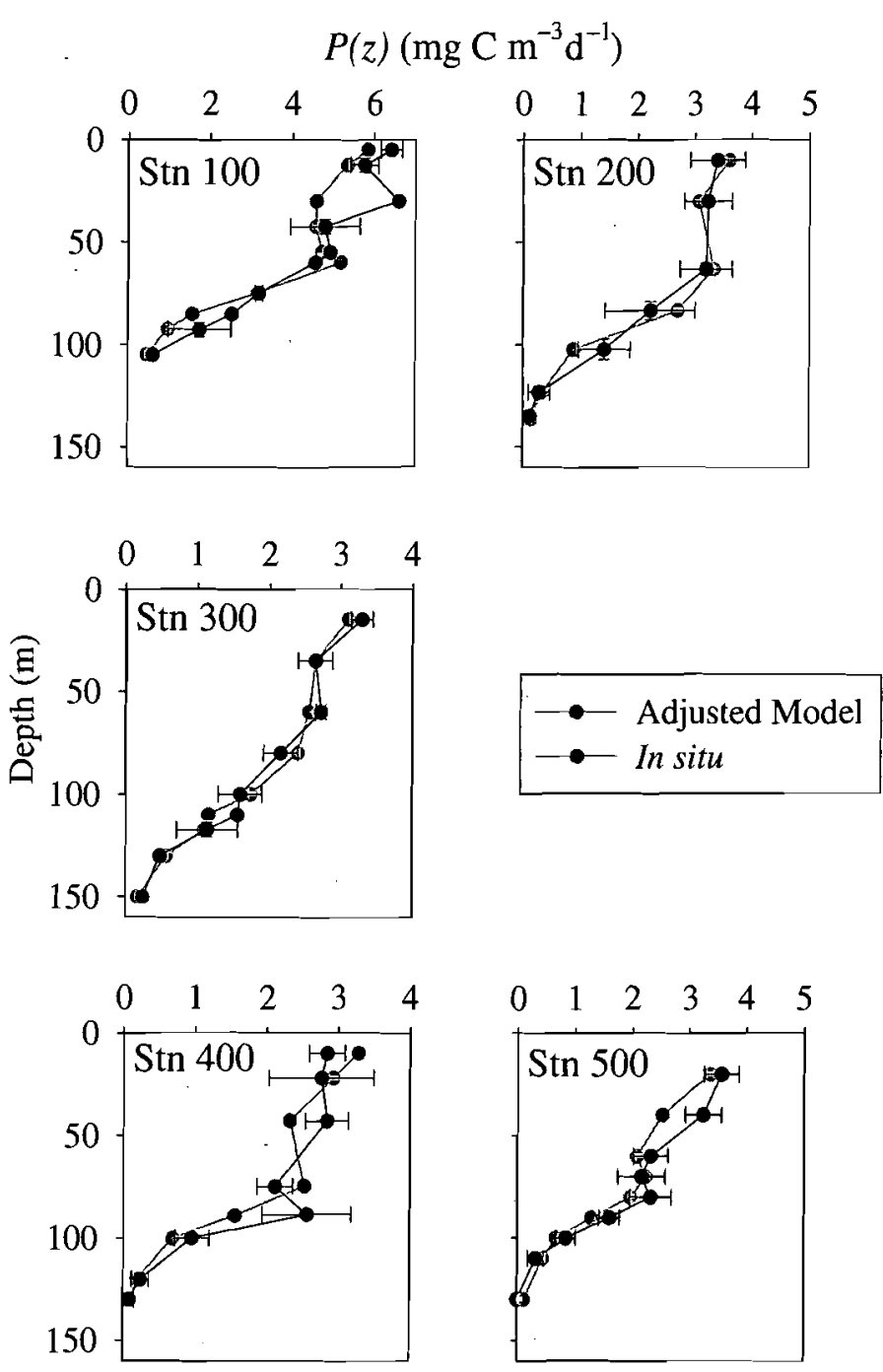

Fig. 6. Mean vertical profiles of primary production estimates generated using the adjusted model parameters and in situ primary production measurements. Mean values of in situ ${ }^{13} \mathrm{C}$ production were computed from 2 sets of observations for Stns 100 and 3 sets of observations for Stns 200 to 500 . Error bars shown on the in situ profiles represent \pm 1 standard deviation from the mean

time and space independently of phytoplankton absorption. Therefore, it may be more appropriate that absorption by yellow substances be modelled on a province-by-province basis, similar to the approach used for the P-I and biomass profile parameters used in primary production models (e.g. Platt \& Sathyendranath 1988), instead of assigning a universal relationship between absorption by phytoplankton and yellow substances. Appropriate representation of all absorptive components of the aquatic medium in light attenuation algorithms can serve only to improve further our models of light attenuation, primary production and ocean colour. 


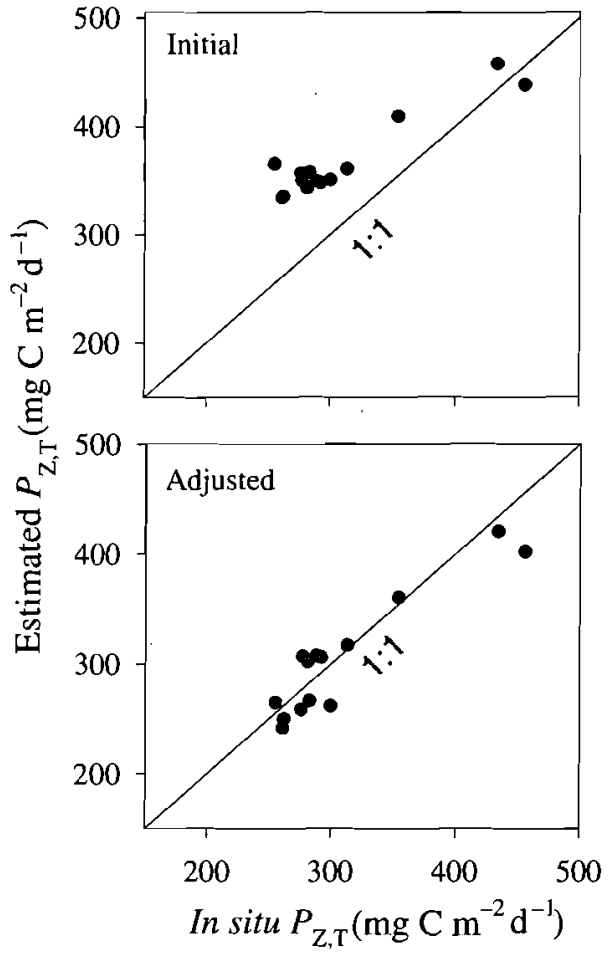

Fig. 7. Estimates of computed, daily, water-column primary production $P_{\mathrm{Z}, \mathrm{T}}$ using the initial (top panel) and adjusted (bottom panel) versions of the spectral model plotted against the in situ measurements of $P_{\mathrm{Z}, \mathrm{T}}$ for the 5 main stations. The solid line is the $1: 1$ relation

\section{Influence of NPPs on estimates of primary production using a spectral model}

We have seen in the results and discussion presented above that by ignoring the variation in absorption by yellow substances we might be introducing serious errors in our estimates of daily, water-column primary production. Another potential source of error when using a bio-optical approach to compute estimates of primary production is in the assignment of a shape to represent the wavelength dependence of $\alpha(\lambda)$. Because the experimental measurement of the photosynthetic action spectrum is time-consuming and labour-intensive, biological oceanographers have sought alternative approaches to approximate the shape of $\alpha(\lambda)$. Two of the most common methods of approximating the photosynthetic action spectrum are by measuring the fluorescence excitation spectrum and the absorption spectrum of phytoplankton. Numerous studies have shown a strong resemblance between the shapes of the absorption and photosynthetic action spectra of phytoplankton (Haxo \& Blinks 1950, Lewis et al. 1988, Kyewalyanga et al. 1997).
Certain algae (e.g. cyanobacteria) are known to have a difference in the composition of light-harvesting pig-' ments between the 2 photosystems, which has been shown to cause a striking difference between the shapes of the absorption and action spectra obtained using either the ${ }^{14} \mathrm{C}$ method (Lewis et al. 1986, 1988, Bidigare et al. 1989, Warnock 1990) or the fluorescence excitation spectrum (Johnsen \& Sakshaug 1996). Where such algae dominate, the absorption spectrum might be compromised as a proxy for the action spectrum. But, in the stations we sampled, although cyanobacteria were present in the water column at all 5 stations sampled in this study, Prochlorococcus was the most dominant alga present, both numerically and in terms of contribution to total chlorophyll a concentration. Further, a study by Moore et al. (1995) showed a very strong agreement between the fluorescence excitation and the absorption spectrum of phytoplankton that was corrected for the absorption by NPPs. It should also be noted that cyanobacteria typically are more abundant and contribute a larger fraction to the total phytoplankton biomass in the surface waters. On the other hand, Prochlorococcus and pico-eukaryotic cells tend to dominate deeper in the water column, and will therefore have more of an impact in the computation of light-limited photosynthesis. Therefore, in this modelling exercise we selected the absorption of phytoplankton pigments as a proxy for the shape of the action spectrum (Haxo \& Blinks 1950, Lewis et al. 1988, Kyewalyanga et al. 1997).

The implicit assumption, often made in production models that incorporate phytoplankton absorption, is that photochemical processes utilise all of the absorbed light energy and that the transfer of absorbed photon energy to reaction centres occurs with a fixed efficiency. However, a group of pigments exists whose absorbed energy is not transferred to the reaction centres of photosynthesis, nor is it fluoresced; instead, the energy is dissipated in the form of heat. It is believed that these NPPs serve a photoprotective role in the cell, and therefore are often referred to as photoprotective pigments (Siefermann-Harms 1987). Therefore, if substantial proportions of NPPs were present in field samples, the use of the spectral shape of phytoplankton absorption by all pigments $\left[a_{\mathrm{ph}}(\lambda)\right]$ to estimate the shape of the photosynthetic action spectrum would not be fully justified (Sakshaug et al. 1991, Sosik \& Mitchell 1995). In the following paragraphs, we will examine the influence NPPs have on the shape of $a_{\mathrm{ph}}(\lambda)$ and on our computations of daily, integrated, water-column primary production.

Using HPLC-determined pigment concentrations, Bouman et al. (2000) observed high proportions of NPPs relative to photosynthetic pigments at the sea surface for all 5 stations. The weight-to-weight ratio of 
NPPs to total pigment, termed the NPP index (Babin et al. 1996), decreased in a systematic manner with increasing depth. In this region it appeared that the vertical change in the NPP index was likely a combined result of photoacclimation and shifts in species composition with depth (Bouman et al. 2000).

This depth-dependent variation in pigment composition was manifested in the optical characteristics of the water column. Differences in the shape of photosynthetic and non-photosynthetic absorption spectra were greatest in samples collected close to the sea surface (Fig. 8). On the other hand, for samples collected close to the DCM, the shapes of photosynthetic and total absorption spectra were nearly identical (Fig. 8).

It has been suggested that, when approximating the shape of the photosynthetic action spectrum, spectral models of primary production should incorporate the shape of the photosynthetically-active absorption spectrum instead of the absorption by both photosynthetic and non-photosynthetic pigments (Sakshaug et al. 1991, Sosik \& Mitchell 1995). However, few studies have quantified the errors associated with using the absorption by these pigments to represent $\alpha(\lambda)$ in computations of primary production. In this study, we calculated the percent relative error introduced into computations of primary production when absorption by NPPs is included in approximating the shape of $\alpha(\lambda)$ as follows.

First, the spectral production model was implemented using the shape of the total absorption spectra of the phytoplankton at depth $z_{1} a_{\mathrm{ph}}(z, \lambda)$, to represent the action spectrum (Model A). Next, the model was re-executed using the absorption spectra of photosyn- thetically-active pigments, $a_{\mathrm{ps}}(z, \lambda)$, for the shape of the action spectrum (Model B). The spectral shape of $a_{\mathrm{ps}}(z, \lambda)$ was estimated by adopting the method of Babin et al. (1996), which uses HPLC pigment concentrations and the pigment-specific absorption coefficients for different pigment groups (Bidigare et al. 1990). The error was then computed by taking the predicted production value of Model A and subtracting it from the production estimate of Model B corresponding to the same depth. This difference was then divided by the production estimate calculated using Model B to obtain relative error. The depth profiles of the relative error are shown in Fig. 9. All 5 stations showed similar vertical trends, with relatively negligible errors at the surface, elevated errors computed at intermediate depths ( 30 to $50 \mathrm{~m}$ ) and a decreasing and eventual levelling off of errors towards the bottom of the photic zone.

It may seem counterintuitive that at the surface, where the influence of NPPs on the shape of the phytoplankton absorption spectrum is the strongest, the difference between production estimates computed using $a_{\mathrm{ps}}(z, \lambda)$ and $a_{\mathrm{ph}}(z, \lambda)$ as proxies for the action spectrum is minimal. To interpret these results it is necessary that both the optical and physiological characteristics of the region be considered simultaneously. Since surface irradiances are typically in the light-saturated region of the photosynthetic response curve, the assimilation number, $P_{\mathrm{m}}^{B}$, governs the modelled rate of photosynthesis, and therefore changes in the spectral shape of $\alpha(z, \lambda)$ will have a minimal impact in this region of the water column. The depth interval in which light-limited photosynthesis influences the computation of primary production is dependent on the magnitudes and vertical distribution of both $\alpha^{B}$ and $P_{\mathrm{m}}^{B}$, and the intensity of surface irradiance. Results presented in Fig. 9 show that the error in production estimates increases from the surface down to between 30 and $50 \mathrm{~m}$ in our study area. At these intermediate depths, errors begin to decrease with depth. This reduction in error is caused by the gradual convergence in the shapes of $a_{p s}(z, \lambda)$ and $a_{p h}(z, \lambda)$ with increasing depth. Towards the bottom of the photic zone, the spectral shape of phytoplankton absorption is determined predominant by the absorptive characteristics of photosynthetic pigments.
Fig. 8. Absorption spectrum of absorption by all pigments (Total) and absorption by photosynthetic pigments (Total-NPP) for water samples collected at Stn 500. Left panel shows a surface sample collected at $20 \mathrm{~m}$. Right panel shows a sample collected below the DCM $(120 \mathrm{~m})$ 

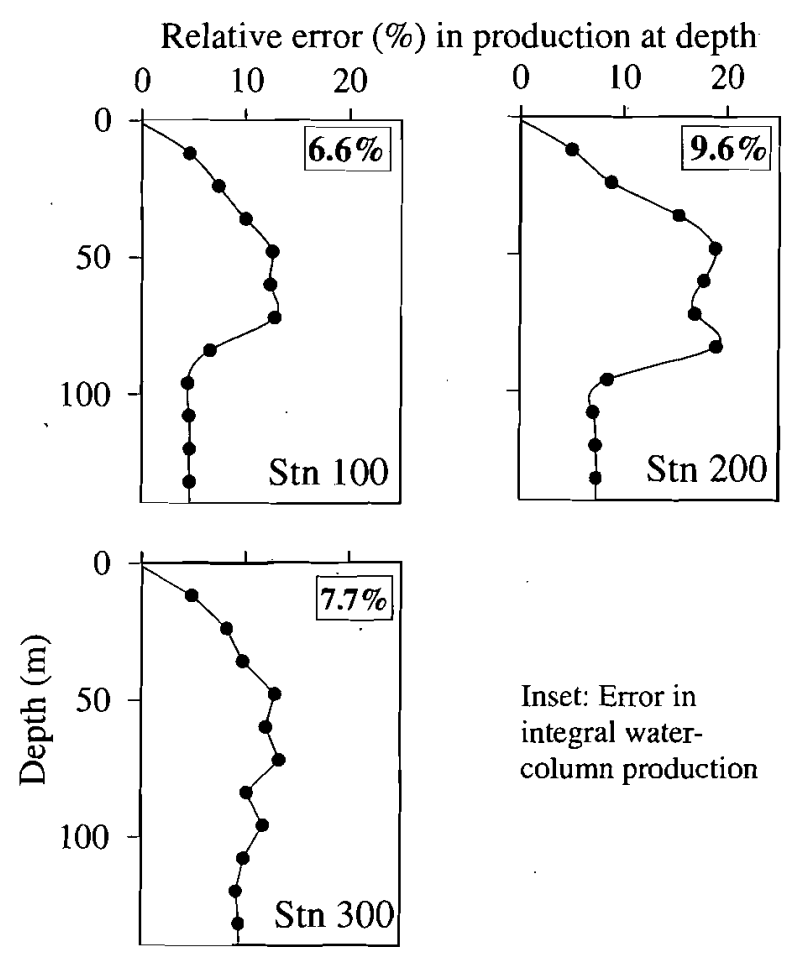

Inset: Error in integral watercolumn production
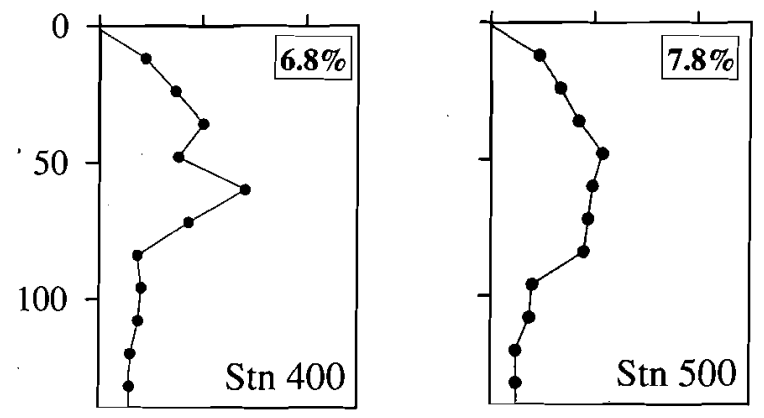

Fig. 9. Profiles of relative error $(\%)$ in the estimation of primary production at depth when total absorption by phytoplankton $a_{\mathrm{ph}}(z, \lambda)$, instead of absorption by photosynthetic pigments $a_{\mathrm{ps}}(z, \lambda)$, is used to represent the wavelengthdependence of light-limited photosynthesis $\alpha(z, \lambda)$

The potential errors associated with the computation of daily, integrated, water-column production are also relatively small: about $6 \%$ on average. This is not unexpected, since production is highest in the upper portion of the water column, where the errors associated with the influence of NPPs on the approximation of $\alpha(z, \lambda)$ are negligible. Therefore, based on the results obtained in this modelling exercise, failing to correct for the absorption of light by NPPs when using the absorption spectrum of phytoplankton as a proxy for the photosynthetic action spectrum would not introduce a serious bias to estimates of daily, water-column primary production.

\section{CONCLUSION}

Since NPPs influence strongly the vertical variation in the shape of phytoplankton absorption spectra in subtropical regions of the ocean, one would expect that by using the absorption spectrum of phytoplankton to estimate the action spectrum in spectral models of production, model estimates would be in serious error. However, results obtained in this study suggest that absorption by NPPs introduces only a minor bias in estimates of primary production when the shape of $a_{\mathrm{ph}}(z, \lambda)$ is used to approximate the shape of $\alpha(z, \lambda)$. Although NPPs have an important influence on the absorptive properties of the phytoplankton at the surface, production in this region of the water column is governed mainly by a parameter that defines the photosynthetic rate at light saturation, $P_{\mathrm{m}}^{B}$. Therefore, regardless of whether $a_{\mathrm{ph}}(z, \lambda)$ or $a_{\mathrm{ps}}(z, \lambda)$ is used to approximate $\alpha(z, \lambda)$ in the spectral model of photosynthesis, production estimates at the surface will be essentially the same. As we approach light-limiting irradiances deeper in the water column, the increase in the intracellular concentration of photosynthetic pigments cause the spectral shapes of $a_{\mathrm{ph}}(z, \lambda)$ and $a_{\mathrm{ps}}(z, \lambda)$ to converge. Therefore, production models that use either of these spectra to approximate the action spectra will yield similar results at depth.

Until recently, yellow substances were considered to contribute only little to the optical variability of the open ocean. Although this may be the case within the mixed layer, it appears from the results obtained in this and other studies (Siegel \& Michaels 1996, Nelson et al. 1998) that non-algal coloured materials can be responsible for a large fraction of the attenuation of blue light below the mixed layer. Furthermore, by failing to incorporate this increased attenuation of blue light by yellow substances below the mixed layer into our computations of primary production, we could be introducing significant errors (up to $30 \%$ ) into our estimates of daily, integrated, water-column primary production. Thus, in addition to the photosynthetic parameters, models of primary production must incorporate the variability in all optical components that influence the propagation of irradiance through the water column. Although absorption by phytoplankton has been routinely measured for purposes of primary production and underwater-irradiance modelling, until recently, relatively few measurements of absorption of the dissolved coloured substances have been made in the open ocean. In the absence of information on the global, spatial and temporal variation in absorption by yellow substances, it remains an open question whether the strong absorption by yellow substances noted at the BATS site and in this study are unusual observations of rare occurrences or, rather, are routine 
manifestations of the typical optical conditions in stratified, subtropical open-ocean waters.

\begin{abstract}
Acknowledgements. We thank Glen Harrison and Les Harris for providing the ${ }^{13} \mathrm{C}$ primary production data, Ingrid Obernosterer for providing the UV data, Kees Veth and Margriet Hiehle for access to the CTD data, and Taco de Bruin for providing data management support for the expedition. We also thank the chief scientist of the DCM expedition, Marcel Veldhuis, and the officers and crew of RV 'Tydeman' for their cooperation throughout the DCM cruise. This work was supported by Natural Sciences and Engineering Research Council of Canada operating grants to T.P. and S.S. This work was carried out as part of the Canadian contribution to the Joint Global Ocean Flux Study (JFOFS). The expedition was supported by the Netherlands Geosciences Foundation (GOA) with additional financial aid from the Netherlands Organization for Scientific Research (NWO), the Netherlands Institute of Sea Research (NIOZ), University of Groningen (Department of Marine Biology) and the Bedford lnstitute of Oceanography.
\end{abstract}

\section{LITERATURE CITED}

Allali K, Bricaud A, Claustre $H$ (1997) Spatial variations in the chlorophyll-specific absorption coefficients of phytoplankton and photosynthetically active pigments in the equatorial Pacific. J Geophys Res 102:12413-12423

Babin M, Morel A, Claustre H, Bricaud A, Kolber Z, Falkowski PJ (1996) Nitrogen- and irradiance-dependent variations of maximum quantum yield of carbon fixation in eutrophic, mesotrophic and oligotrophic marine systems. Deep-Sea Res 43:1241-1272

Bidigare RR، Schofield O, Prézelin BB (1989) Influence of zeaxanthin on quantum yield of photosynthesis of Synechococcus clone WH7803 (DC2). Mar Ecol Prog Ser 56: $177-188$

Bidigare RR, Ondrusek ME, Marrow JH, Kiefer DA (1990) In vivo absorption of algal pigments. SPIE 1302:290-302

Bird RE (1984) A simple, solar spectral model for direct-normal and diffuse horizontal irradiance. Sol Energy 32:461-471

Bouman HA, Platt T, Kraay GW, Sathyendranath S, Irwin BD (2000) Bio-optical properties of the subtropical North Atlantic. I. Vertical variability. Mar Ecol Prog Ser

Bricaud A, Morel A, Prieur L (1981) Absorption by dissolved organic matter of the sea (yellow substance) in the UV and visible domains. Limnol Oceanogr 26:43-53

Cullen JJ (1982) The deep chlorophyll maximum: comparing vertical profiles of chlorophyll a. Can J Fish Aquat Sci 39: 791-803

Cullen JJ, Lewis MR, Davis CO, Barber RT (1992) Photosynthetic characteristics and estimated growth rates indicate grazing is the proximate control of primary production in the equatorial Pacific. J Geophys Res 97:639-654

Garver SA, Siegel DA (1997) Inherent optical property of ocean color spectra and its biogeochemical interpretation. 1. Time series from the Sargasso Sea. J Geophys Res 102: 18607-18625

Haxo FT, Blinks LR (1950) Photosynthetic action spectra of marine algae. J Gen Physiol 33:389-422

Herbland A (1983) Le maximum de chlorophylle dans l'Atlantique tropical oriental: description, écologie, interprétation. Oceanog Trop 18:295-318
Hoepffner N, Sathyendranath S (1992) Bio-optical characteristics of coastal waters: Absorption spectra of phytoplankton and pigment distribution in the western North Atlantic. Limnol Oceanogr 37:1660-1679

Hoepffner N, Sathyendranath S (1993) Determination of the major groups of phytoplankton pigments from the absorption spectra of total particulate matter. J Geophys Res 98: 22789-22803

Holm-Hansen O, Lorenzen CJ, Holmes JDH (1965) Fluorometric determination of chlorophyll. J Cons lnt Explor Mer 30:3-15

Jassby AD, Platt T (1976) Mathematical formulation of the relationship between photosynthesis and light for phytoplankton. Limnol Oceanogr 21:540-547

Jerlov NG (1968) Optical oceanography. Elsevier Oceanography Series, Vol 5. Elsevier Publishing Company, Amsterdam

Johnsen G, Sakshaug E (1996) Light harvesting in bloomforming marine phytoplankton: species-specifity and photoacclimation. Sci Mar 60 (Suppl 1):47-56

Kirk JTO (1976) Yellow substance (gelbstoff) and its contribution to the attenuation of photosynthetically active radiation in some inland and coastal south-eastern Australian waters. Aust J Mar Freshw Res 27:61-71

Kirk JTO (1994) Light and photosynthesis in aquatic ecosystems. Cambridge University Press, Cambridge

Kraay GW, Zapata M, Veldhuis MJW (1992) Separation of chlorophylls $c 1, c 2$, and $c 3$ of marine phytoplankton by reversed-phase-c18-high-performance liquid chromatography. J Phycol 28:708-712

Kyewalyanga M, Platt T, Sathyendranath S (1992) Ocean primary production calculated by spectral and broad-band models. Mar Ecol Prog Ser 85:171-185

Kyewalyanga MN, Platt T, Sathyendranath S (1997) Estimation of the photosynthetic action spectrum: implication for primary production models. Mar Ecol Prog Ser 146: 207-223

Lazzara L, Bricaud A, Claustre H (1996) Spectral absorption and fluorescence excitation properties of phytoplanktonic populations at a mesotrophic and an oligotrophic site in the tropical North Atlantic (EUMELI program). Deep-Sea Res 43:1215-1240

Lewis MR, Warnock RE, Platt $T$ (1986) Photosynthetic response of marihe picoplankton at low photon flux. Can Bull Fish Aquat Sci 214:235-250

Lewis MR, Ulloa O, Platt T (1988) Photosynthetic action, absorption, and quantum yield spectra for a natural population of Oscillatoria in the North Atlantic. Limnol Oceanogr 33:92-98

Moore LR, Goericke R, Chisholm SW (1995) Comparative physiology of Synechococcus and Prochlorococcus: influence of light and temperature on growth, pigments, fluorescence and absorptive properties. Mar Ecol Prog Ser $116: 259-275$

Morel A (1974) Optical properties of pure seawater. In: Jerlov NG, Steemann Nielsen E (eds) Optical aspects of oceanography. Academic Press, New York, p 1-24

Morel A (1978) Available, usable, and stored radiant energy in relation to marine photosynthesis. Deep-Sea Res 125 : 673-688

Morel A (1980) In-water and remote measurement of ocean color. Boundary-Layer Meteorol 18:177-201

Morel A, Antoine D, Babin M, Dandonneau Y (1996) Measured and modeled primary production in the northeast Atlantic (EUMELI JGOFS program): the impact of natural variations in photosynthetic parameters on model predictive skill. Deep-Sea Res 43:1273-1304 
Negri RM, Carreto JI, Benavides HR, Akselman R, Lutz VA (1992) An unusual bloom of Gyrodinium cf. aureolum in the Argentine Sea: community structure and conditioning factors. J Plankton Res 14:261-269

Nelson NB, Siegel DA, Michaels AF (1998) Seasonal dynamics of colored dissolved material in the Sargasso Sea Deep-Sea Res 45:931-957

Platt T, Sathyendranath S (1988) Oceanic primary production: estimation by remote sensing at local and regional scales. Science 241:1613-1620

Platt T, Gallegos CL, Harrison WG (1980) Photoinhibition of photosynthesis in natural assemblages of marine phytoplankton. J Mar Res 38:687-701

Platt T, Sathyendranath S, Caverhill CM, Lewis MR (1988) Ocean primary production and available light: further algorithms for remote sensing. Deep-Sea Res 35:855-879

Platt T, Caverhill C, Sathyendranath S (1991) Basin-scale estimates of oceanic primary production by remote sensing: the North Atlantic. J Geophys Res 96:15147-15159

Platt T, Sathyendranath S, Ulloa $\odot$, Harrison WG, Hoepffner N, Goes J (1992) Nutrient control of phytoplankton photosynthesis in the western North Atlantic. Nature 356: 229-231

Pope RM, Fry ES (1997) Absorption spectrum (380-700 nm) of pure water. II. Integrating cavity measurements. Appl Optics 36:8710-8723

Prieur L, Sathyendranath S (1981) An optical classification of coastal and oceanic waters based on the specific spectral absorption curves of phytoplankton pigments, dissolved organic matter, and other particulate materials. Limnol Oceanogr 26:671-689

Sakshaug E, Johnsen G, Andresen K, Vernet M (1991) Modeling of light-dependent algal photosynthesis and growth: experiments with the Barents Sea diatoms Thalassiosira nordenskioeldii and Chaetoceros furcellatus. Deep-Sea Res 38:415-430

Sakshaug E, Bricaud A, Dandonneau Y, Falkowski PG, Keifer DA, Legendre L; Morel A, Parslow J, Takahashi M (1997) Parameters of photosynthesis: definitions, theory and interpretation of results. J Plankton Res 19:1637-1670

Sathyendranath S, Platt $T$ (1988) The spectral irradiance field at the surface and in the interior of the ocean: a model for applications in oceanography and remote sensing. J Geophys Res 93:9270-9280

Editorial responsibility: Otto Kinne (Editor),

Oldendorf/Luhe, Germany
Sathyendranath S, Platt T (1989) Computation of aquatic primary production: extended formalism to include effect of angular and spectral distribution of light. Limnol Oceanogr 34:188-198

Sathyendranath S, Platt T, Caverhill CM, Warnock RE, Lewis MR (1989) Remote sensing of oceanic primary production: Computations using a spectral model. Deep-Sea Res 36: 431-453

Schofield O, Prézelin BB, Smith RC, Stegmann PM, Nelson NB, Lewis MR ${ }_{r}$ Baker KS (1991). Variability in spectral and nonspectral measurements of photosynthetic light utilization efficiencies. Mar Ecol Prog Ser 78:253-271

Siefermann-Harms D (1987) The light-harvesting and protective functions of carotenoids in photosynthetic membranes. Physiol Plant 69:561-568

Siegel DA, Michaels AF (1996) Quantification of non-algal light attenuation in the Sargasso Sea: implications for biogeochemistry and remote sensing. Deep-Sea Res 1143 : 321-345

Smith RC, Baker KS (1981) Optical properties of the clearest natural waters (200-800 nm). Appl Optics 20:177-184

Sosik HM, Mitchell BG (1995) Light absorption by phytoplankton, photosynthetic pigments and detritus in the California Current System. Deep-Sea Res 42:1717-1748

Veldhuis MJW, Kraay GW (1990) Vertical distribution and pigment composition of a picoplankton prochlorophyte in the subtropical North Atlantic: a combined study of HPLCanalysis of pigments and flow cytometry. Mar Ecol Prog Ser 68:121-127

Vodacek A, Blough NV, DeGrandpre MD, Peltzer ET, Nelson RK (1997) Seasonal variation of CDOM and DOC in the Middle Atlantic Bight: terrestrial inputs and photooxidation. Limnol Oceanogr 42:674-686

Warnock RE (1990) Photosynthetic characteristics of picoplankton and natural phytoplankton assemblages. PhD dissertation, Dalhousie University, Halifax

Wernand MR, Spitzer D (1987) Processing of underwater spectra collected by ASIR (Advanced Spectr. IRad.meter) in the Madura Bay. In: Proceedings of the joint DFVLRLAPAN-NIOZ workshop on remote sensing of the sea. Participation in the Snellius ll expedition 1984, Jan 14 to 16, 1987, Jakarta, Indonesia, Reference Publication, TKH 8705 Indonesian National Institute of Aeronautics and Space (LAPAN), Jakarta, p 160-166

Submitted: June 14, 1999; Accepted: November 5, 1999 Proofs received from author(s): June 21, 2000 